\title{
A economia simbólica da cultura popular sertanejo-nordestina
}

Elder Patrick Maia Alves

Curso: Doutorado em Sociologia

Data da defesa: 25 de junho de 2009

Orientadora: Prof ${ }^{a}$ Dr $^{a}$ Mariza Veloso Motta Santos

\section{Resumo}

Este trabalho tem como horizonte temático as transformações ocorridas no âmbito da produção simbólico-cultural contemporânea, notadamente no que diz respeito às novas faces e fases do processo de industrialização do simbólico com as políticas culturais públicas. Diante dessa temática, a pesquisa buscou objetivar precisamente as interfaces entre determinadas políticas culturais públicas e o advento de uma nova formação discursiva (o repertório discursivo Unesco) para a estruturação de um mercado de bens e serviços 
culturais bastante específico, ancorado fundamentalmente no valor social conferido a categorias como tradição e "autenticidade". As interfaces entre os processos mencionados plasmaram uma rede de interdependências assaz complexa, integrada por distintos planos empíricos, tensões políticas e lutas culturais, além de processos intersubjetivos, como o consumo simbólico e a construção social do gosto.

O objetivo do trabalho consiste, assim, em desvelar e compreender os principais eixos de tessitura dessa rede, composta simultaneamente por quatro processos: 1) os impactos da intensificação do processo de industrialização do simbólico (hoje também digitalização do simbólico); 2) o advento de uma nova formação discursiva em âmbito transnacional, tributária das lutas político-culturais em defesa da diversidade cultural, da identidade e das chamadas culturas tradicionais e populares, lutas essas marcadas pelas novas relações entre as categorias de cultura e desenvolvimento; 3) a implementação de determinadas políticas culturais (como o Programa Cultura Viva e o Programa Nacional do Patrimônio Imaterial - PNPI), que atualizam e potencializam o valor social atribuído às categorias de tradição e "autenticidade", pondo em circulação alguns signos institucionais de distinção, como os pontos de cultura e o título de Patrimônio Cultural do Brasil, muitas vezes utilizados com objetivos políticos e econômicos; 4) o consumo simbólico orientado pela busca da experiência de consumir bens e serviços culturais reputados como profundamente "autênticos" e tradicionais, como a literatura de cordel, os objetos de barro da arte figurativa e o forró/baião, presentes em determinadas linguagens artísticas, como o cinema, o teatro e a literatura. Esses quatro processos conjugados configuram a economia simbólica da cultura popular sertanejo-nordestina.

Palavras-chave: cultura popular; sertão; economia simbólica. 